Mini Review

\title{
Analysis of Bean Products and Genetically Modified Soybean Using Electroanalytical Methods: A Mini Review
}

\author{
Yuanxi Deng ${ }^{1 *}$, Jie $\mathrm{Wu}^{1}$, Kang $\mathrm{Tu}^{2,{ }^{*}}$, Hui $\mathrm{Xu}^{1}$, Long $\mathrm{Ma}^{1}$, Jia Chen ${ }^{1}$ and Jialiang Wang ${ }^{1}$ \\ ${ }^{1}$ College of Food and Bioengineering, Bengbu University, Anhui, 233030. P.R. China \\ ${ }^{2}$ College of Food Science and Technology, Nanjing Agricultural University, Jiangsu, 210095, P.R. \\ China \\ *E-mail: 278967574@qq.com Kangtu163@foxmail.com
}

doi: $10.20964 / 2019.07 .70$

Received: 1 April 2019 / Accepted: 10 May 2019 / Published: 10 June 2019

\begin{abstract}
Bean products are a common type of food in human daily diets. Analysis of bean products is not only related to the food industry but also to the dietary health of consumers. In this review, we summarize the results of electrochemical analysis and detection of some effective substances in bean products, including soybean isoflavones and biogenic amines. In addition, we describe in detail the detection of genetically modified soybean based on electrochemical sensors. This review will help food practitioners to understand the current research trends of electrochemical analysis of bean products and the future prospects in this field.
\end{abstract}

Keywords: Bean product; Analytical methods; Review; Electrochemistry; Food chemistry

\section{$\underline{\text { FULL TEXT }}$}

(C) 2019 The Authors. Published by ESG (www.electrochemsci.org). This article is an open access article distributed under the terms and conditions of the Creative Commons Attribution license (http://creativecommons.org/licenses/by/4.0/). 